\title{
AUTOEFICÁCIA ACADÊMICA: POSSIBILIDADE PARA REFLETIR SOBRE O ENSINO MÉDIO
}

\author{
Roberta Gurgel Azzi* \\ Daniela Couto Guerreiro-Casanova**
}

Marilda Aperecida Dantas***

Este artigo dedica-se a uma reflexão sobre aspectos relacionados ao Ensino Médio e busca compreendê-los à luz de uma análise da percepção de alunos dessa faixa relativa ao constructo autoeficácia acadêmica. Tal constructo refere-se às crenças do aluno na capacidade em organizar e executar cursos de açóes, requeridos para produzir realizaçóes quanto aos aspectos intelectuais e de aprendizagem. Por meio de uma escala, com 31 itens, em formato Likert de 7 pontos, analisaram-se as percepções de 165 alunos do Ensino Médio, de uma escola privada e duas escolas estaduais, localizadas no Estado de São Paulo. Destes, 116 são do gênero feminino e 48 do masculino, com idades entre 14 $(18,5 \%)$ e $24(0,6 \%)$ anos. Discutem-se os cinco itens com médias mais altas e os cinco com as mais baixas. A análise descritiva revelou alta percepção de autoeficácia acadêmica. Analisam-se os dados encontrados pontuando a necessidade de investigaçôes e reflexôes complementares para ampliar a compreensão dos resultados aqui apresentados.

Palavras-chave: Autoeficácia. Ensino Médio. Protagonismo.
*Pós-doutorado em Psicologia - UFSCar; Doutora em Educação - Unicamp; Docente - Unicamp.

Campinas, SP - Brasil

**Doutoranda em Educação Unicamp.

Campinas, SP - Brasil

***Doutoranda em Educação Unicamp.

Campinas, SP - Brasil 


\section{Introdução}

Nos últimos anos a ampliação do acesso à educação formal pôde ser verificada em praticamente todos os níveis de ensino. Considerando-se o acesso, sabe-se que 63\% dos jovens entre 15 e 24 anos estudam, sendo que destes $41 \%$ cursam o Ensino Fundamental, 53\% cursam o Ensino Médio e apenas 6\% frequentam o Ensino Superior (SPOSITO, 2008). De acordo com o Censo Escolar, no Brasil em 2009 havia 8.337.160 alunos frequentando o Ensino Médio (Inep, 2009). Apesar de a ampliação do acesso ao Ensino Médio ser considerada como um aspecto positivo há preocupação a respeito da sua qualidade. Analisando-se o Índice de Desenvolvimento da Educação Básica (Ideb) relativo ao ano de 2009, percebemos que o Ensino Médio, assim como o Ensino Fundamental alcançaram médias compatíveis com as metas estabelecidas. Porém, o crescimento da média demonstrado pelo Ensino Médio foi tímido, passando de 3,5 em 2007 para 3,6 em 2009, se comparado ao crescimento da média demonstrado nos anos iniciais e nos anos finais do Ensino Fundamental (de 4,2 a 4,6 nos anos iniciais e de 3,8 a 4,0 nos anos finais).

O Ensino Médio é a etapa da educação que tem desencadeado maior inquietação nos aspectos envolvidos nas dificuldades de acesso e na qualidade da educação oferecida, bem como nos aspectos que permeiam a constituição dos seus objetivos educacionais e curriculares. A clara delimitação desses objetivos coloca-se como aspecto de suma relevância, a fim de garantir equidade de oportunidades. Todavia, esse aspecto demonstra náo ser tão facilmente alcançado, pois, apenas nos últimos dez anos, o Ensino Médio já sofreu duas propostas de reformas curriculares (KRAWCZYK, 2009), e especialistas ainda clamam pela necessidade de mais alteraçôes (SALDANÃ; STANISCI; LORDELO, 2010). Esse quadro evidencia a dificuldade de aplicação da proposta curricular, independente de qual seja, pois, usualmente a compreensão dos docentes em relação a elas demanda tempo e formação, bem como percepção de valia atribuída a tais propostas (ZIBAS; FERRETTI; TARTUCE, 2006). 
Sem dedicar, neste texto, maior aprofundamento para a discussão das questóes relativas aos objetivos e ao currículo, ressalta-se que as Diretrizes Curriculares Nacionais para o Ensino Médio apresentam, entre outros, o "protagonismo juvenil" como um princípio fundamental. "Tal concepção privilegia a participaçáo de jovens no desenvolvimento das atividades voltadas para a construçáo de conhecimentos e valores, cabendo ao professor mais a função de orientar do que a de ensinar" (ZIBAS; FERRETTI; TARTUCE, 2006 , p. 53). Possivelmente, a grande valia do princípio do protagonismo juvenil seja a perceptível adaptabilidade deste às características do ciclo de vida no qual os alunos do Ensino Médio encontram-se: a adolescência. Esta é a fase da vida em que se inicia a busca pela autonomia, marcada tanto pela construção de elementos da identidade pessoal e coletiva quanto por uma atitude de experimentação (SPOSITO, 2008), compreendendo o alongamento da transição entre a infância e a vida adulta, a escolaridade como etapa intrínseca à condiçáo juvenil, o retardamento da entrada no mundo do trabalho e o aparecimento de formas de consumo e de produção cultural típicas desse segmento (SPOSITO, 2004). No entanto, devido à diversidade da juventude atual, a escola não consegue reconhecer o seu aluno e encontra dificuldades para implantar o protagonismo juvenil na realidade escolar (ZIBAS; FERRETTI; TARTUCE, 2006).

Nesse contexto, o aluno do Ensino Médio frequenta escola que nem sempre está preparada para conhecê-lo e para atendê-lo. Esse despreparo pode estar na origem de posturas estudantis tidas como incompatíveis com o espaço escolar, sendo interpretadas e rotuladas como falta de motivaçáo para aprender (COSTA; BORUCHOVITCH, 2006).

A respeito dessa temática, a pesquisa "Perfil da Juventude Brasileira" (SPOSITO, 2008) revela que, o tema "educaçáo" interessa aos jovens, por representar a possibilidade para discutir o presente e o futuro, objetivando a inserção na sociedade. Dos 3051 jovens entrevistados, $76 \%$ percebem a escola como muito importante em relação à perspectiva profissional, 58\% 
percebem seus benefícios no presente, 74\% acham que a escola é importante para compreender a realidade. Essas percepçóes podem indicar que a instituição escolar "[...] está assegurada no horizonte juvenil, o que implica em investir nas mudanças interiores das mesmas e aos seus significados" (SPOSITO, p.109, 2008).

Diante do cenário até aqui apresentado nota-se que o Ensino Médio é um dos espaços educacionais que merecem mais investigaçóes e reflexóes. Neste artigo buscamos contribuir com a produção deste nível de ensino, a partir de uma análise sobre o Ensino Médio, fundamentado na Teoria Social Cognitiva de Albert Bandura (BANDURA, 2008). Tal escolha pauta-se na crença de que essa visão da psicologia pode auxiliar na compreensão de processos que ocorrem no interior da escola. A discussão aqui apresentada é parte integrante de pesquisa, ainda em desenvolvimento, "Motivação no Ensino Médio: explorando relaçóes entre variáveis motivacionais", coordenada por Azzi, de modo que os dados e as análises discutidos correspondem a uma parcela do vasto repertório de dados obtidos na referida pesquisa. Destacamos, também, a análise da percepção de alunos do Ensino Médio relativa ao constructo "autoeficácia acadêmica".

\section{Autoeficácia acadêmica}

A crença de autoeficácia é um constructo referente a diversos domínios, portanto, específico a cada contexto (BANDURA, 1997). Neste artigo a "autoeficácia acadêmica" constitui o domínio de interesse. Registramos que Bandura e seus colaboradores iniciaram as pesquisas da crença de eficácia no domínio acadêmico em 1983, verificando que a "autoeficácia acadêmica”, definida como as crenças de um estudante em sua capacidade em organizar e executar cursos de ações requeridos para produzir certas realizaçóes, referentes aos aspectos intelectuais e de aprendizagem, coloca-se como um constructo necessário à pos- 
tura requerida do estudante (BANDURA, 1993). As crenças de autoeficácia acadêmica são construídas ao longo da vida por meio de quatro fontes de informação: experiência direta de domínio, experiência vicária, persuasão social, estado físico e emocional. Esse processo de construção da crença de autoeficácia torna-a dinâmica, de modo que uma pessoa pode julgar-se capaz de realizar determinada tarefa em um momento específico, mas em outro, nem tanto. É interessante pontuar que a autoeficácia acadêmica refere-se à percepção que um aluno tem sobre a sua capacidade para realizar determinada tarefa escolar e que não é relativa ao julgamento sobre os atributos físicos e/ou de personalidade dos alunos (ZIMMERMAN; CLEARY, 2006).

Os estudos têm evidenciado que a autoeficácia acadêmica age como mediadora da motivação (BANDURA, 1993; COSTA; BORUCHOVICTH, 2006; SCHUNK, 1995; ZIMMERMAN; CLEARY, 2006). Desse modo, um estudante com autoeficácia acadêmica forte demonstrará maior esforço, mais persistência, interesse e propósito para aprender, pois a intensidade da crença de autoeficácia acadêmica exerce impacto na qualidade e quantidade de investimento que cada estudante dedica à seleção e à realização de tarefas de aprendizagem, afetando o desempenho, inclusive o da habilidade de memória, pois o afeta direta e indiretamente de modo a melhorá-lo, mesmo quando há obstáculos para a realização do objetivo proposto. Na perspectiva da Teoria Social Cognitiva as habilidades são entendidas como um atributo adquirido e mutável, no qual o indivíduo pode exercer controle, por meio da prática e do seu desenvolvimento. (BANDURA, 1993; SCHUNK, 1995; ZIMMERMAN; CLEARY, 2006).

Segundo Bandura (1993; 1997), as crenças dos estudantes em suas capacidades de realização em assuntos escolares predizem suas conquistas educacionais subsequentes. Isso alivia a ansiedade educacional e colabora para a construção da autoeficácia acadêmica, bem como para o desenvolvimento de capacidades cognitivas e de habilidades auto-reguladoras, as quais gerenciam as tarefas acadêmicas e os padróes de pensamento. Segundo Schunk (1995) o 
1 Esse é o objetivo que norteia a discussão neste artigo, náo retratando a totalidade de objetivos da pesquisa Motivação no Ensino Médio: explorando relaçōes entre variáveis motivacionais. O número de escolas e de alunos participantes citados neste artigo também não representa todos os participantes da pesquisa completa.

2 A pesquisa só se realizou após a aprovação pelo Comitê de Ética em Pesquisa, da Universidade Estadual de Campinas, sob no CAAE 0912.0.146.00009 , assim como após autorização das diretoras das escolas em que foram coletados os dados.

\footnotetext{
3 Essa escala encontra-se em processo de validação. Foi desenvolvida a partir da Escala de Autoeficácia na Formação Superior (POLYDORO; GUERREIRO-CASANOVA, no prelo).
}

pressuposto geral é de que, quanto mais bem percebida a crença de autoeficácia acadêmica melhor os estudantes se organizam/mobilizam para completar os trabalhos educacionais, respeitam as datas estabelecidas e mantém-se em atividades escolares mesmo quando há outras mais interessantes a fazer, podendo demonstrar melhor desempenho acadêmico.

\section{Quem escutamos}

A partir dessa compreensão teórica, e com o objetivo ${ }^{1}$ de identificar a percepção de autoeficácia acadêmica de alunos do Ensino Médio, fomos a quatro escolas ${ }^{2}$ do nível em pauta. Dessas, três eram públicas e uma privada, sendo duas localizadas em um município da regiáo metropolitana e duas localizadas no interior do Estado de São Paulo. A discussão realizada, neste artigo, é referente à percepção de 165 alunos de Ensino Médio, sendo 79 alunos do primeiro ano, 42 do segundo e 44 do terceiro. Destes, 116 são do gênero feminino e 48 do masculino, com idades entre 14 (18,5\%) e $24(0,6 \%)$ anos, sendo que os alunos com 15 anos (30,9\%), com 16 anos $(22,8 \%)$ e com 17 anos $(18,5 \%)$ representam a maior parte da amostra. Todos os menores de 18 anos tiveram autorização dos pais/responsáveis para participarem da pesquisa. Dentre os 165 alunos pesquisados, a maior parte (63\%) estuda no período noturno e a menor parte trabalha $(34,4 \%)$.

A percepçấo desses alunos foi obtida por meio das respostas oferecidas em uma escala destinada à mensuração da autoeficácia acadêmica ${ }^{3}$ de alunos do Ensino Médio. Essa escala conta com 31 itens, em formato Likert de 7 pontos, sendo (1) para pouco e (7) para muito. Trata-se de escala de autorelato que solicita ao estudante análise em relaçáo à sua capacidade de realizar as diversas situaçōes incluídas na vida acadêmica, abrangendo aspectos envolvidos no processo de aprendizagem (organização, domínio de conteúdo, realização das atividades), condiçóes de estudo (organizar o tempo, persistência 
diante de dificuldades, motivação) e desempenho do estudante (sistematização das informaçóes, acompanhamento do ritmo de aprendizagem do curso, capacidade de colocar em prática os conhecimentos adquiridos). De maneira geral, os alunos participantes responderam a essa escala em suas próprias salas de aula, durante as aulas de Português. Casos excepcionais em que a adesão à participação foi baixa, entre os alunos de uma determinada turma, a coleta de dados foi realizada em outra sala, de modo que a maioria não participante continuasse atividades com a professora.

\section{A percepção desses alunos}

$\mathrm{Na}$ quase totalidade dos itens $(\mathrm{n}=30)$, as médias obtidas foram maiores do que quatro (sete era o valor máximo), apenas um item teve média inferior a quatro. Diante da tendência de alta percepção de eficácia, expressa por valores superiores a quatro, decidiu-se, neste artigo, discutir os cinco itens que demonstraram maiores médias e outros cinco que revelaram menores médias, analisando-os por série. As comparaçôes entre as médias das séries aqui apresentadas náo foram analisadas estatisticamente, a fim de identificar suas significâncias, contudo, decidiu-se mostrar tais médias, de modo a estimular uma análise específica a cada série do Ensino Médio, contribuindo para um diagnóstico mais próximo da realidade de cada grupo de alunos. Para facilitar a visualizaçáo dos dados vamos apresentá-los resumidamente na Tabela 1 para, em seguida, discutir seu conteúdo na continuidade do texto.

Observa-se, nessa tabela, que mesmo polarizando os itens que obtiveram resultados de médias mais baixas e mais altas, a diferença entre um e outro ainda é relativamente pequena. Na classe de itens de médias mais baixas, vale notar tendência de aumento na transiçáo da $2^{\text {a }}$ para a $3^{\mathrm{a}}$ série, enquanto que, nas médias mais altas, há uma tendência de aumento na transição entre $1^{\circ}$ e $2^{\circ}$ ano. A seguir, a análise discutida item a item. 


\section{Tabela 1: Dados descritivos da autoeficácia acadêmica de alunos do Ensino Médio}

\begin{tabular}{|c|c|c|c|c|c|c|c|}
\hline & \multirow{2}{*}{$\begin{array}{c}\text { Item } \\
\text { Quanto eu sou } \\
\text { capaz de... } \\
\end{array}$} & \multicolumn{2}{|c|}{$1^{\mathrm{a}}$ série } & \multicolumn{2}{|c|}{$2^{\mathrm{a}}$ série } & \multicolumn{2}{|c|}{$3^{a}$ série } \\
\hline & & média & $\begin{array}{l}\text { desvio } \\
\text { padrão }\end{array}$ & média & $\begin{array}{l}\text { desvio } \\
\text { padrão }\end{array}$ & média & $\begin{array}{l}\text { desvio } \\
\text { padrão }\end{array}$ \\
\hline \multirow{5}{*}{ 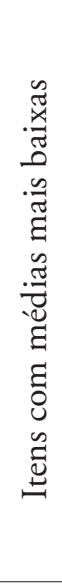 } & $\begin{array}{c}\text { Pedir ajuda aos } \\
\text { colegas nas atividades } \\
\text { desta disciplina? }\end{array}$ & 4,68 & 1,96 & 5,00 & 1,93 & 4,47 & 2,14 \\
\hline & $\begin{array}{c}\text { Contribuir com ideias } \\
\text { para a melhoria da } \\
\text { minha escola? }\end{array}$ & 4,96 & 1,94 & 4,47 & 1,92 & 4,58 & 1,90 \\
\hline & $\begin{array}{l}\text { Buscar informaçóes } \\
\text { sobre a infraestrutura } \\
\text { e recursos da escola } \\
\text { que frequento? }\end{array}$ & 4,10 & 2,08 & 3,59 & 1,80 & 3,68 & 1,69 \\
\hline & $\begin{array}{l}\text { Estudar quando existem } \\
\text { outras coisas para fazer? }\end{array}$ & 4,24 & 1,82 & 4,59 & 1,49 & 4,52 & 1,81 \\
\hline & $\begin{array}{c}\text { Revisar o conteúdo } \\
\text { desta disciplina? }\end{array}$ & 4,74 & 1,79 & 4,73 & 1,43 & 4,90 & 1,53 \\
\hline \multirow{5}{*}{ 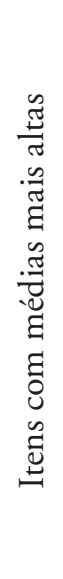 } & $\begin{array}{c}\text { Estabelecer bom relacio- } \\
\text { namento com o profes- } \\
\text { sor desta disciplina? }\end{array}$ & 6,14 & 1,21 & 6,10 & 1,15 & 6,40 & 1,14 \\
\hline & $\begin{array}{l}\text { Terminar os trabalhos } \\
\text { solicitados nesta } \\
\text { disciplina dentro do } \\
\text { prazo estabelecido? }\end{array}$ & 6,16 & 1,22 & 6,35 & 0,95 & 6,11 & 1,29 \\
\hline & $\begin{array}{l}\text { Cumprir as normas da } \\
\text { escola que frequento? }\end{array}$ & 5,87 & 1,43 & 5,95 & 1,23 & 6,30 & 1,15 \\
\hline & $\begin{array}{l}\text { Planejar ações para } \\
\text { atingir meus objetivos } \\
\text { profissionais? }\end{array}$ & 5,54 & 1,58 & 6,16 & 1,18 & 6,18 & 1,00 \\
\hline & $\begin{array}{l}\text { Aprender o conteúdo } \\
\text { desta disciplina? }\end{array}$ & 5,74 & 1,09 & 5,95 & 0,98 & 5,65 & 1,36 \\
\hline
\end{tabular}

Fonte: as autoras. 
O item em que os alunos demonstraram maior percepção foi o correspondente à capacidade de "estabelecer bom relacionamento com o professor da disciplina Língua-Portuguesa”. Essa percepção positiva obteve média 6,14 (desvio padrão $=1,21$ ) para os alunos da $1^{\text {a }}$ série, apresentou ligeiro declínio para os alunos da $2^{\text {a }}$ série, com média 6,10 (desvio padrão $=1,15$ ) e ligeira ascensão na $3^{\text {a }}$ série, com média 6,40(desvio padrão = 1,14). Essa percepção dos alunos parece mostrar que o relacionamento entre alunos e docente, na disciplina Língua-Portuguesa, é bom. Esta informação é interessante, pois devido às inúmeras queixas usualmente realizadas pelos docentes sobre os aspectos comportamentais dos alunos, náo era esperada uma percepção tão alta relativa a esse aspecto.

A segunda percepção de autoeficácia acadêmica mais alta é referente à capacidade de "terminar os trabalhos solicitados na disciplina dentro do prazo estabelecido". Nesse item, os alunos da $1^{\text {a }}$ série demonstraram média 6,16 (desvio padrão $=1,22$ ), os da 2a série, média 6,35 (desvio padrão $=0,95)$, com ligeiro declínio para os alunos da $3^{a}$ série, com média 6,11 (desvio padrão = 1,29). Não dispomos de dados sobre o comportamento estudantil de entrega de tarefas nos prazos estabelecidos por professores, mas, certamente, a percepção dos estudantes de que têm condiçôes de se organizar para isso, fica sinalizada. Por outro lado, essa percepçáo torna-se ainda mais curiosa quando confrontada com a percepção demonstrada em relação à capacidade de "estudar quando existem outras coisas para fazer", cuja média foi uma das mais baixas, revelando médias 4,24 (desvio padrão $=1,82$ ) para a $1^{\text {a }}$ série, $4,59$ (desvio padrão $=1,49)$ para a $2^{\text {a }}$ série e $4,52($ desvio padrão $=1,81)$ para a $3^{\text {a }}$ série. A princípio, esses dados parecem demonstrar que os alunos têm condiçôes de cumprirem os prazos estabelecidos pelos docentes, contudo, deixam o estudo para segundo plano quando existem outras atividades. Nesse caso, pode-se problematizar essa situação segundo o valor conferido à educação pela juventude, aqui representada por 165 alunos, bem como pela comunidade à qual esses alunos pertencem. Apesar de, como comentado anteriormente, 
os jovens acharem que a escola é importante para compreender a realidade e para o preparo profissional (SPOSITO, 2008), os alunos integrantes desta pesquisa parecem náo conseguir manter o foco na dedicaçáo ao estudo em etapas intermediárias que se fazem necessárias para o alcance de resultados desejados que se encontram mais distantes. Considerando que parte desses jovens $(n=56)$ já exercerem algum atividade profissional, o desenvolvimento de estratégias que possibilitem conciliar o tempo entre estudo e trabalho, sem prejuízo a ambos, parece ser um caminho promissor para que os alunos consigam dar conta dos compromissos acadêmicos e profissionais. De acordo com a literatura, a alta percepção da autoeficácia acadêmica tem sido relacionada com bom desempenho acadêmico, no entanto, somente a percepção de eficácia sem as habilidades e/ou os conteúdos prévios necessários não proporciona a aprendizagem. (BANDURA, 1993; SCHUNK, 1995; ZIMMERMAN; CLEARY, 2006). As habilidades podem ser desenvolvidas por meio da prática. Nesse sentido, buscar condiçóes mobilizadoras para que os alunos pratiquem, apliquem e relacionem os conteúdos ensinados, faz-se de suma importância de modo que, desenvolver açóes a fim de valorizar as atividades educacionais, relacionando-as com a prática e com a realidade do aluno, constitui um dos grandes desafios conferidos ao ensino médio, reforçando a necessidade de se repensar a proposta pedagógica desse nível de ensino.

Outro item que se destaca, por ter obtido uma das médias mais altas, é o relativo à percepção dos alunos em relação à capacidade para "cumprir as normas da escola que frequentam". A percepção dessa capacidade aumentou entre as séries, obtendo médias 5,87 (desvio padrão $=1,43$ ) na $1^{\text {a }}$ série, 5,95 (desvio padrão $=1,23$ ) na $2^{\text {a }}$ série e 6,30 (desvio padrão $\left.=1,15\right)$ na $3^{\text {a }}$ série. Em meio a tantas queixas sobre indisciplina escolar, essa alta percepção surpreende. Uma possibilidade de análise seria interpretar essa informaçáo de modo literal, ou seja, eles percebem que são capazes de cumprir as normas, mas isso não é sinônimo de que as normas sejam cumpridas. A análise de dois itens que obtiveram as cinco mais baixas médias pode auxiliar a busca para 
a compreensão. Os alunos demonstraram médias baixas para a percepção da capacidade relativa a "contribuir com ideias para a melhoria da escola", sendo médias 4,96 (desvio padrão = 1,94) para os alunos da $1^{\text {a }}$ série, 4,47 (desvio padrão $=1,92)$ para a $2^{\text {a }}$ série e $4,58($ desvio padrão $=1,90)$ para a $3^{\text {a }}$ série. Também foi baixa a percepção da capacidade relativa a "buscar informaçôes sobre a infra-estrutura e recursos da escola que frequenta", sendo médias 4,10 (desvio padrão $=2,08)$ para a $1^{\text {a }}$ série, $3,59($ desvio padrão $=1,8)$ para a $2^{\text {a }}$ série e 3,68 (desvio padrão $=1,69$ ) para a $3^{\text {a }}$ série. Nesses dois itens, as médias verificadas para os alunos da $2^{\text {a }}$ série foram mais baixas do que as verificadas para os alunos da $1^{\mathrm{a}}$ série, contrário ao esperado, pois seria aceitável que o aluno da $1^{a}$ série tivesse menor percepção em relação a esses itens, se for considerada a possibilidade de que a $1^{\text {a }}$ série de um nível de ensino constitui período de transição. Uma possível problematização sobre esses resultados seria a de que esses alunos ( $2^{\text {a }}$ série) mostram que não se integraram plenamente à escola ou não se sentem parte da mesma, pois, apesar das médias subirem na $3^{a}$ série ( média $=4,58$, desvio padrão $=1,90$ e média $=3,68$, desvio padrão $=1,69$ respectivamente), são menores do que as demonstradas na $1^{\text {a }}$ série. Assim, possivelmente, por não se perceberem parte integrante da escola, esses alunos não valorizem aspectos gerais do cotidiano escolar.

Diante dessas colocações, é interessante retomar o conceito de protagonismo juvenil, que "privilegia a participação de jovens no desenvolvimento das atividades voltadas para a construção de conhecimentos e valores" (ZIBAS; FERRETTI; TARTUCE, 2006, p. 53). Nota-se a necessidade de proporcionar condiçôes para que os alunos possam exercer o protagonismo juvenil por meio da participação em atividades escolares, a fim de se sentirem parte integrante da escola. A oferta de espaço para a contribuição de ideias na melhoria da escola, busca de informações sobre a sua infraestrutura e cumprimento de normas, possivelmente seriam açóes valorizadas pelos educandos, as quais poderiam contribuir para a valorização do cotidiano escolar. 
Em relação a esse processo, a percepção relativa à própria capacidade para aprender o conteúdo de Português foi uma das cinco mais altas demonstradas por essa amostra. Para esse item, os alunos da $1^{\text {a }}$ série apresentaram média 5,74 (desvio padrão $=1,09)$, os da $2^{\text {a }}$ série, 5,95 (desvio padrão $\left.=0,98\right)$ e os da $3^{\text {a }}$ série, demonstraram média 5,65 (desvio padrão = 1,36). Ao olhar mais atentamente, percebemos que houve um ligeiro movimento de ascensão da $1^{\mathrm{a}}$ para a $2^{\mathrm{a}}$ série, seguido de declínio para a $3^{\mathrm{a}}$ série. Pode-se levantar a hipótese de que as exigências acadêmicas do Ensino Médio foram mais bem compreendidas pelos alunos das $2^{\text {a }}$ série, após terem vivenciado um ano de adaptação, sendo que o declínio ocorrido na $3^{\mathrm{a}}$ série pode ser decorrente da "pressão" relativa ao final do curso e às incertezas vivenciadas durante o último ano do Ensino Médio, como também, podem ser decorrentes da maior complexidade dos conteúdos ensinados nesse ano.

Cabe destacar o item "revisar o conteúdo da disciplina", no qual os alunos demonstraram uma das menores médias. Neste item, os alunos da $1^{\mathrm{a}}$ série obtiveram média 4,74 (desvio padrão $=1,79$ ), os da 2a série mostraram média 4,73 (desvio padrão $=1,43$ ) e, os da 3a série, obtiveram média 4,90 (desvio padrão $=1,53$ ). Essas percepçóes mais baixas podem demonstrar que alunos dessa amostra não se sentem tão capazes de revisar o conteúdo da disciplina. Como a ação de revisar o conteúdo constituiu uma das atividades fundamentais para o processo de aprendizagem, cabe refletir se essa percepção mais baixa pode ser decorrente da falta de conhecimento sobre o como realizar essa estratégia de aprendizagem, ou de não conseguirem se planejar para realizá-la.

Outra condição envolvida no contexto de aprendizagem em que os alunos demonstraram uma das menores percepçóes é relativa ao item "pedir ajuda aos colegas nas atividades da disciplina Português". Neste item, os alunos da $1^{\text {a }}$ série demonstraram média 4,68 (desvio padrão $=1,96$ ), os da $2^{\text {a }}$ série mostraram uma percepção pouco maior, com média 5,0 (desvio padrão $=1,93$ ) e, os alunos da $3^{\text {a }}$ série, demonstraram média 4,47 (desvio padrão = 2,14 ), sendo menor do que a média da $1^{\text {a }}$ série. Destaca-se essa menor percep- 
ção, pois, sob a ótica da Teoria Social Cognitiva, os alunos podem aprender com as experiências acadêmicas vividas por seus pares, ampliando os padróes de modelos e de comparaçóes, o que constitui uma importante estratégia de aprendizagem (BANDURA, 1997; SCHUNK, 1995). Caberia aqui, então, uma questão: o que pode justificar tal resultado? Mediante a análise dos itens "revisar o conteúdo da disciplina" e "pedir ajuda aos colegas nas atividades da disciplina Português", pode-se ressaltar a importância das estratégias de aprendizagem para o desempenho dos alunos. Desse modo, destaca-se que, somente a percepção positiva de autoeficácia acadêmica não é suficiente para garantir a aprendizagem, sendo necessário conhecimento prévio, habilidades, reconhecimento sobre contribuição que determinada atividade poderá proporcionar e estratégias de aprendizagem autoreguladas (SCHUNK, 1995).

$\mathrm{O}$ último item a ser discutido é relativo à percepção da capacidade de "planejar açôes para atingir os objetivos profissionais" relativos ao ensino médio. Neste item, as médias elevaram-se no decorrer das séries, de modo que os alunos da $1^{\mathrm{a}}$ série demonstraram média 5,54 (desvio padrão = 1,58), os da $2^{\text {a }}$ série com média 6,16 (desvio padrão $=1,18$ ) e, os da $3^{\mathrm{a}}$ série obtiveram média 6,18 (desvio padrão = 1,00). Esse dado parece indicar que a vivência durante os três anos de Ensino Médio altera a percepção desses alunos em relação à capacidade de planejar ações para atingir os objetivos profissionais, fortificando-a. É interessante associar esse dado com a informação divulgada por Sposito (2008), retratando que $76 \%$ dos jovens percebem a escola como muito importante em relação à perspectiva profissional.

\section{Consideraçóes finais}

Ao olhar as percepçóes reveladas pelos 165 alunos integrantes da amostra analisada, podem-se levantar questionamentos que contribuam para pensar a prática pedagógica realizada no Ensino Médio. Ainda que os dados desta 
pesquisa não retratem as diversas realidades desses alunos na medida em que apenas estudantes de quatro escolas participaram do estudo, as reflexóes aqui discutidas podem estimular uma postura investigativa em relação à percepçáo das crenças de autoeficácia acadêmica de alunos do referido nível de ensino. Também servem de alerta para a necessidade de se considerar características próprias de cada série, nas tendências claras nas percepçóes captadas pela pesquisa que possibilitam encaminhamentos diferenciados no campo pedagógico.

Como discutido anteriormente, as percepçôes de eficácia acadêmica dos participantes deste estudo tenderam para valores superiores ao ponto médio. Dessa primeira análise sobre as percepçóes de autoeficácia acadêmica de alunos do Ensino Médio destaca-se a necessidade de se investir em estratégias autoreguladas de ensino e de aprendizagem. Isto porque, se a positiva percepção de autoeficácia acadêmica verificada na amostra se mantiver na totalidade dos participantes da pesquisa, a hipótese de que os alunos têm uma positiva percepção sobre a autoeficácia acadêmica, mas não sabem como utilizar estratégias cognitivas para direcionar e organizar a construção de conhecimento pode ganhar mais força. É interessante destacar que apenas a positiva percepção de autoeficácia acadêmica não garante a aprendizagem (BANDURA, 1997; SCHUNK, 1995), porém, como destacam Azzi e Polydoro (2010) no processo motivacional, as pessoas que acreditam que suas açóes podem produzir os resultados desejados, tendem a ter um incentivo a agir e persistir frente a dificuldades. Vale ressaltar que a crença é um fator que pode possibilitar a utilização de estratégias autoreguladas de aprendizagem, como estabelecimento de metas e objetivos, seleção e adoção de estratégias de aprendizagem, além de ser um elemento chave para a motivação a aprender (ZIMMERMAN; CLEARY, 2006). Contudo, a positiva percepção de autoeficácia acadêmica identificada nesses alunos pode ser considerada um resultado desejável, ainda que possa estar superestimada, pois uma percepção de eficácia levemente superestimada pode contribuir para elevar a motivação e o desempenho dos alunos (SCHUNK; MEECE, 2006). 
Acredita-se que a maior compreensão sobre as percepçóes de autoeficácia acadêmica, bem como sobre os aspectos que a compóem, possa contribuir para enriquecer as experiências de ensino e de aprendizagem no Ensino Médio. Espera-se que este artigo tenha contribuído para aguçar a reflexão sobre o constructo aqui discutido e suas contribuições para a prática educativa.

\section{ACADEMIC SELF EFFICACY: CHANCE TO REFLECT ABOUT HIGH SCHOOL}

This article is dedicated to a reflection on high school related issues and aims to understand these through the analysis of the perceptions of high school students regarding academic self efficacy construct. This construct refers to the beliefs of the student's ability to organize and execute courses of actions required to attain designated types of intellectual and learning performance. Through a scale of 31 items on 7-point Likert format, we analyzed the perceptions of 165 high school students, at one private school and two public schools located in the state of Sao Paulo. Of these, 116 are females and 48 males, age range between $14(18.5 \%)$ to $24(0.6 \%)$ years. It discusses the five items with the highest and lowest average scores. The descriptive analysis revealed a high sense of academic self efficacy. We discuss our data pointing out the need for additional research and reflections to increase the understanding of the results presented here.

KeY wORDs: Self efficacy. High school. Protagonism.

\section{Referências}

AZZI, R. G.; POLYDORO, S. A. J. O papel da autoeficácia e autorregulação no processo motivacional. In: BORUCHOVITCH, E.; BZUNECK, J. A.; GUIMARÃESM S. E. R. Motivaçâo para aprender: aplicaçôes no contexto educativo. Petropólis: Vozes. 2010. p. 126-144. 
Motivação no Ensino Médio: explorando relaçóes entre variáveis motivacionais (Projeto de Pesquisa). Campinas: Universidade Estadual de Campinas, 2009.

BANDURA, A. Perceived self-efficacy in cognitive development and functiong. Educational Psychologist, v. 28, n. 2, p. 117-148. 1993.

Self-efficacy: The exercise of control. New York: W. H. Freeman, 1997.

A evolução da teoria social cognitiva. In: BANDURA, A.; AZZI, R. G.; POLYDORO, S. (Org.). Teoria social cognitiva, conceitos básicos. Porto Alegre: Artmed, 2008. p. 15-42.

COSTA, E. R.; BORUCHOVITCH, E. A autoeficácia e a motivação para aprender. In: AZZI, R. G.; POLYDORO, S. A. J. (Org.). Auto-eficácia em diferentes contextos. Campinas: Alinea. 2006. p. 87-109.

INSTITUTO NACIONAL DE EDUCAÇÃO E PESQUISA (Inep). Censo Educação

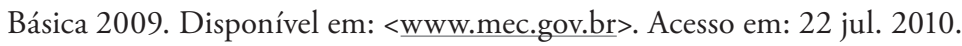

Resultados Índice de Desenvolvimento da Educação Básica 2009. Disponível em: <www.mec.gov.br>. Acesso em: 10 jul. 2010

KRAWCZYK, N. O ensino médio no Brasil. São Paulo: Ação Educativa, 2009.

SALDANÃ, P.; STANISCI, C.; LORDELO, C. Especialistas veem falta de professores e pedem reforma do ensino médio O Estado de S. Paulo, versão on-line. Disponível em: <www.estadao.com.br>. Acesso em: 1o jul. 2010.

SCHUNK, D. H. Self-efficacy and education and instruction. In: MADDUX, J. E. (ed.) Self-efficacy, adaptation and adjustment- theory, research and application. New York: Plenum Press, 1995. p. 281-303.

.; MEECE, J. L. Self-efficacy development in adolescence. In: PAJARES, F.;

URDAN, T. (Org.). Self-efficay beliefs of adolescents. Connecticut: Information Age Publishing, p. $71-96,2006$.

SPOSITO, M. P. Algumas reflexóes e muitas indagaçóes sobre as relaçóes entre juventude e escola no Brasil. In: ABRAMO, H. W.; BRANCO, P. P. M. (Org.). Retratos da juventude brasileira. Análises de uma pesquisa nacional. São Paulo: Editora Fundação Perseu Abramo, 2008. p. 87-127. 
(Des)encontros entre os jovens e a escola. In: FRIGOTO, G.; CAIVATTA, M. (Org.). Ensino Médio - ciência, cultura e trabalho. Brasília, DF: MEC, SEMTEC, fev. 2004. p.73-91.

POLYDORO, S. A. J; GUERREIRO-CASANOVA, D.C. Escala de auto-eficácia na formação superior: construção e estudo de validação. Avaliação Psicológica. (no prelo).

ZIBAS, D. M. L.; FERRETTI, C. J.; TARTUCE, G. L. B. P. Micropolítica escolar e estratégias para o desenvolvimento do protagonismo juvenil. Cadernos de Pesquisa. São Paulo, v. 36, n. 127, p.51-58. jan./abr.2006.

ZIMMERMAN, B. J; CLERAY, T. J. Adolescents' development of personal agency. In: PAJARES, F. URDAN, T. (Org.). Self-efficacy beliefs of adolescents. Connecticut: Information Age Publishing, 2006. p. 45-69.

Recebidoem 19jan. 2010 / Aprovado em 21 jun. 2010

Para referenciar este texto

AZZI, R. G.; GUERREIRO-CASANOVA, D. C.; DANTAS, M. A. Autoeficácia acadêmica: possibilidade para refletir sobre o Ensino Médio. EccoS, São Paulo, v. I2, n. I, p. 5I-67, jan./jun. 2010. 
